\title{
Operative temperature and thermal sensation assessments in non-air-conditioned multi- storey hostels in Malaysia
}

\begin{abstract}
This study assessed the influences of operative temperature on occupants' perceptions of indoor thermal condition in three non-air-conditioned multi-storey hostels in Klang Valley, Malaysia. The thermal conditions of 24 measured rooms were recorded with and without an operating ceiling fan from May until July 2007. Measurements were made simultaneously at three different floor levels, namely, at the first, fifth and top floor of each of the case study hostels. A questionnaire survey was completed by 298 female student occupants of the same case study hostels. The results suggested that even though a significance above $p<0.01$ was recorded between the operative temperatures with and without fan operation, the temperature difference remained small, i.e., from $0.5 \mathrm{~K}$ to $1 \mathrm{~K}$. The findings of the questionnaire survey showed that the occupants perceived the thermal conditions in rooms that were shaded with a projected balcony (shading ratio of 0.9 ), a long roof overhang (shading ratio of 1.6) and an operable window-to-wall ratio of 0.3 to be thermally comfortable.
\end{abstract}

Keyword: Non-air-conditioned multi-storey hostel; Operative temperature; Thermal comfort; Fan usage; Balcony; Questionnaire survey 